\title{
Conservation of Metal Objects
}

As mentioned above, the state of preservation of most of the artefacts is very poor. The weapons were made of iron, and although their condition is poor, ironically it is quite stable. Weapons were found to consist entirely of corrosion products, and no longer had an iron core, as illustrated by the tomographic analysis of spear fragment Z16/14 (see Chapter 19, Fig. 19.3, this volume). Therefore, conservation was focused mainly on recording the condition of artefacts, minor cleaning, and consolidation.

Most of the metal elements of the bed frames were cleaned by removing loose particles of sand from their surfaces and reassembling fragments into whole objects where possible. The poor condition of nails and frame fittings (mainly made of iron) did not allow the use of chemical cleaning. It could be very risky to use chemical cleaning fluids in field conditions without the proper equipment. In many cases, iron objects were completely corroded, without the core being preserved.

The conservation of tools was also limited to cleaning their surfaces of dust and gluing together broken fragments. The degree of corrosion of the tools precluded further intervention by chemical means.

In the case of copper-based buckles [Fig. 13.1: a, b] and other copper objects, conservation was carried out in accordance with the standard procedures for objects made of this metal. After recording the condition of each artefact before conservation, they were tested for the presence of active corrosion. None of the items returned a positive test, regardless of the category. The fight against active corrosion was carried out using the Krefting method (in the case of relatively large objects) or the Rosenberg method (in the case of very delicate or less corroded objects) (Safarzyński and Weker 2010, 17-20). Both methods are based on the electrolytic reduction process and used for active corrosion treatment. In the Krefting method, the object is wholly immersed in an electrolytic bath (often a weak acid, such as acetic acid, being used as an electrolyte). There is no external electricity source. The copper object itself acts as an anode, and, for example, aluminium foil can serve as the cathode. In the case of the Rosenberg method, gel (electrolyte) and aluminium foil are applied only on corrosion spots on the object's surface, so more damaged copper objects can be treated this way.

The object was then subjected to a bath in an aqueous solution of a $5 \%$ EDTA (stabilization of corrosion products). Finally, the object was protected with а втА $2 \%$ corrosion inhibitor in a spirit solution and surface-coated with a protective layer of Paraloid B44.

In the case of ferrous objects, such as belt loop Z16/36 (see Chapter 15.2, Cat. 4, this volume), conservation was limited to light surface cleaning from easily removable dust and other fine impurities and gluing the broken parts with a reversible cyanoacrylate adhesive. In 2017 some iron objects from tumulus 1, mainly nails and fittings, were treated in a new way, by boiling in distilled water (desalination, and removal of easily soluble corrosion products). This treatment was carried out three to four times (with changes of water) for 30 minutes. These objects were subsequently drained and degreased in an acetone bath. The effect will be researched by monitoring their condition over the coming years.

The metalwork described in Chapter 18 is not suitable in most cases for any kind of analysis, as its state of preservation is too poor. Metal artefacts (in this case mainly iron) that do not retain their original shape, mass and even quantity cannot be analysed in any rational way. They elude all statistics and categorization, especially since it is often impossible to determine whether all fragments found in a given group represent one or multiple objects.

The gold objects, which were not incrusted with other less resistant materials, did not need any specialist cleaning. Earring $\mathrm{Z1} / 3^{2}$ (see Chapter 5 , Fig. 5.4, this volume) was broken and in the worst state of preservation. Earring $\mathrm{Z}_{4} / 12$ and other artefacts discovered in tumulus $4\left(\mathrm{Z}_{4} / 14\right.$, $\mathrm{Z}_{4} / 96, \mathrm{Z}_{4} / 97, \mathrm{Z}_{4} / 98, \mathrm{Z}_{4} / 213$; see Chapter 5 , Figs $5 \cdot 4,5 \cdot 5$, 5.6, 5.14, and Chapter 6, Fig. 6.1, this volume) were found in good condition; tarnish was present only in the place where the earring had been brazed with tin [Fig. 13.1: c].

Silver objects also survived in good condition. A layer of patina can be present on the surface of good quality silver and prevents the surface from other corrosion. This type of patina was observed on silver bell $\mathrm{Z}_{4} / 11$, silver double wires $\mathrm{Z}_{10} / 46$, and silver pin $\mathrm{Z}_{4} / 212$ [Fig. 13.2]. Silver settings of cabochons survived in much worse condition (see Chapter 5, Figs 5.9-5.13, this volume).

Iron objects exhibit the worst state of preservation. Their poor condition sometimes makes it impossible to determine the function of the object. Many, but not all, of the iron artefacts are fully corroded, without any iron core and only corrosion is extant. In such cases, the objects are very friable. The iron blades, arrowheads, spears and javelins in this assemblage have been severely damaged 

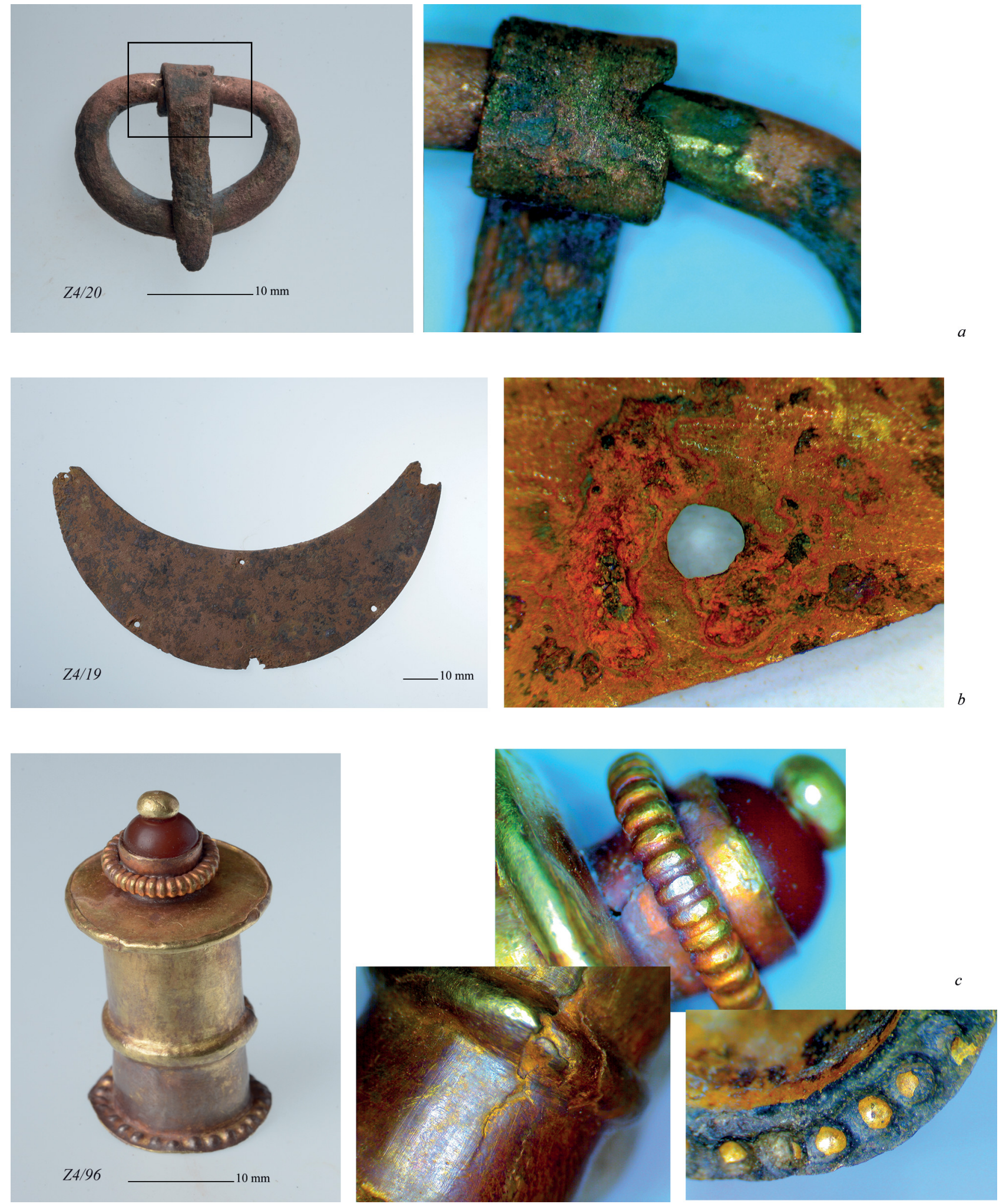

FIGURE 13.1 Traces of corrosion on copper $(\mathrm{a}, \mathrm{b})$ and gold $(\mathrm{c})$ artefacts PHOTOS OF OBJECTS BY A. KAMROWSKI [LEFT]; MACRO PHOTOS BY Ł. ZIELIŃSKI [RIGHT] 

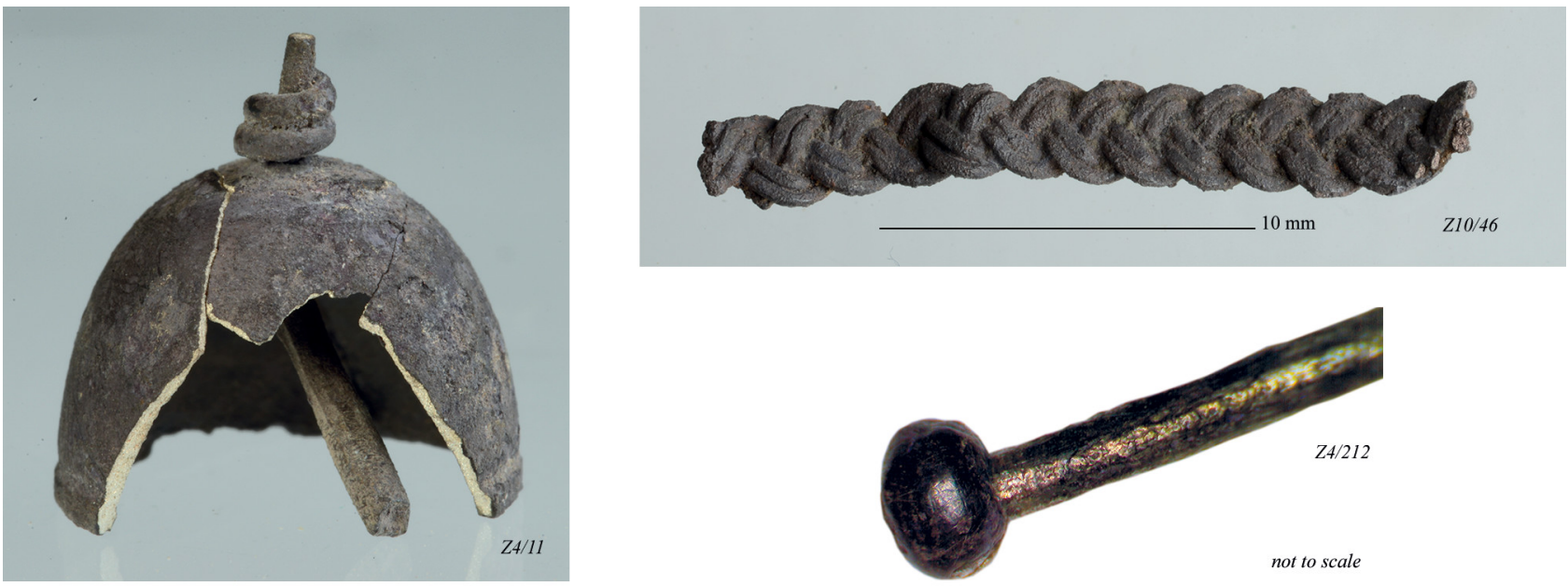

$10 \mathrm{~mm}$

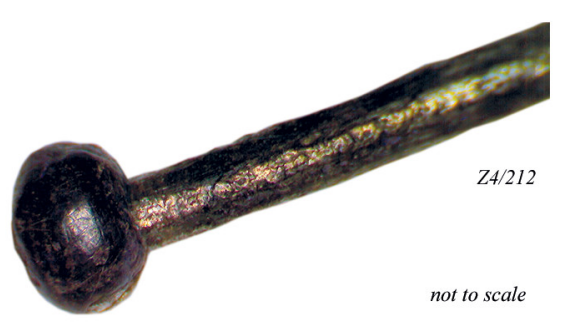

FIGURE 13.2 Traces of patina on the surfaces of silver objects

Z4/11, Z10/46 PHOTOS BY A. KAMROWSKI; Z4/212 PHOTO BY Ł. ZIELIŃSKI

by corrosion, and are often broken. As a result, the individual elements of the weapon are difficult to match and to interpret. Iron elements coated with copper and copper alloys, which in theory should be more resistant to corrosion, are also often severely damaged. It is difficult to attribute them to specific objects because elements such as sleeves were components of both weapons and other items such as tools. Defining the origin of a given element displaced by robber activity proved challenging.

Hardly any elements made of organic raw materials, such as leather and wood, were found in the tumuli at El-Zuma. Sometimes their presence is evidenced only by faint negative impressions in the corrosion surrounding a metal object, or spots of darker soil in which blades or tips appear. Therefore, among the finds from El-Zuma we do not have a complete shaft weapon, arrow or quiver, although we know about their presence thanks to extant projectiles (arrowheads, spearheads, javelin heads) and imprints. 